\title{
ANÁLSE TÉCNICA E FUNDAMENTALISTA: ENSAIOS SOBRE OS MÉTODOS DE ANÁLSE**
}

Thiago de Sousa Barros ${ }^{1}$ - tsousabarros@gmail.com

${ }^{1}$ Universidade Federal de Ouro Preto Minas Gerais/ Brasil

\begin{tabular}{l|l|l} 
* Submissão em: 05/03/2015 & Revisado em: 11/09/2015 & Aceito em: 12/09/2015
\end{tabular}

\begin{abstract}
RESUMO
Este artigo analisa a complementaridade, as distinções e discrepâncias das Ferramentas Fundamentalista e Técnica, utilizadas pelos acionistas em suas tomadas de decisões no mercado de capitais, tema de calorosas discussões entre os agentes do mercado financeiro. Para tanto delimitou-se uma amostra com os 7 ativos com maior volume financeiro transacionado na BM\&F Bovespa, no ano de 2012, e após empregar as metodologias de análise quantitativa dos demonstrativos e gráficos foram observados os fatores de cada método e suas características mais importantes. Os resultados apontaram que as duas técnicas podem ser utilizadas de forma complementar, sendo que uma - a análise técnica busca captar tendências de curto prazo e fazer previsões para esses períodos, enquanto a outra - a análise fundamentalista - é primordial para o conhecimento da situação patrimonial, econômica e financeira das firmas, auxiliando o analista principalmente nas decisões de longo prazo. Por fim, enfatiza-se que para a amostra analisada a BM\&F Bovespa apresentou melhores índices econômicofinanceiros, ao passo que a OGX Petróleo, no histórico de cotações, teve queda acentuada no valor de seus ativos, com grandes prejuízos.
\end{abstract}

Palavras-chave: Análise Fundamentalista. Análise Técnica. Mercado de capitais.

\section{TECHNICAL AND FUNDAMENTALIST ANALYSIS: ESSAYS ON THE METHODS OF ANALYSIS}

\begin{abstract}
This article analyzes the complementarity, distinctions and discrepancies of the Fundamentalist and Technique Tools, used by shareholders in their decision making in the capital market, subject of heated discussions among financial market participants. To this end, delineated a sample with 7 assets with the highest financial volume traded on the BM\&F Bovespa, in 2012, and after employing the methodologies for quantitative analysis of statements and graphics factors of each method and its most important features were observed. Actual results indicated that the two techniques can be used complementarily wherein that a (technical analysis) search to capture short-term trends and make forecasts for those periods, while fundamental analysis is essential for understanding the financial situation, economic and financial firms, helping the analyst primarily in long-term decisions. Finally, it is emphasized that for the sample analyzed BM\&F Bovespa showed better financial ratios while the OGX Petroleo, in the historical quotations, had sharp drop in the value of its assets, with large losses.
\end{abstract}

Keywords: Fundamentalist Analysis. Technical Analysis. Capitals Market. 


\section{INTRODUÇÃ̃}

Com o aperfeiçoamento do mercado financeiro, surgiram as ferramentas de Análise Fundamentalista e Técnica para auxiliar os investidores na tomada de decisão relativamente aos seus ativos financeiros. Esses métodos de análise foram originados há cerca de 30 e 100 anos, respectivamente (PINHEIRO, 2005). Durante vários anos, um dos maiores entraves entre os traders que operam no mercado financeiro decorre da dúvida de quais são as ferramentas mais eficazes utilizadas para a análise de ativos e deste debate derivam as ferramentas de Análise Técnica e Fundamentalista. Esses instrumentos permitem que os analistas calculem os valores inerentes dos ativos, utilizando como comparação o preço de mercado para efetuar a compra e venda destes. Podem também capturar e julgar o desempenho histórico de preço dos ativos e seus volumes transacionados, para avaliar a tendência e a concentração destes no mercado (SCHROEDER, CLARK e CATHEY, 2005).

A Análise Fundamentalista, originou-se no meio acadêmico e a grande maioria dos indivíduos que a utiliza são administradores de fundos e investidores a longo prazo (LOPES e GALDI, 2006). Enquanto que a análise Técnica surgiu no meio profissional do mercado financeiro e grande parte dos seus adeptos são indivíduos com ação especuladora no mercado (WINGER e FRASCA, 1995). Essas diferenças entre as duas ferramentas é dada pelo propósito de responder uma pergunta chave de cada método: "por que adquirir certo ativo?" e “quando é o momento certo da compra/venda de determinado ativo?".

Em traço geral, o método Fundamentalista busca avaliar se há um valor real ou intrínseco que se relaciona diretamente com o desempenho da empresa, ou seja, tem como objetivo determinar o real valor de uma ação (PENMAN, 2004; e BODIE, KANE e MARCUS, 2001). Em contrapartida, a Análise Técnica dedica-se a formar projeções sobre o comportamento das ações a partir de padrões observado no desempenho passado do mercado e utiliza-se de cálculos matemáticos e estatísticos para efetivar sua análise, com o objetivo de determinar a tendência de evoluções das cotações no curto prazo (CHAVES e ROCHA, 2004; e ROTELLA, 1992).

Esta pesquisa tenciona analisar a correlação e a discrepância dos modelos de Análise Fundamentalista e Técnica na tomada de decisão entre compra/venda de uma amostra de ativos financeiros transacionados na BM\&F Bovespa, através da aplicação metodológica das duas ferramentas a sete ativos de cinco companhias de capital aberto, com maior volume transacionado na BM\&F Bovespa no exercício de 2012, a fim de confirmar as similaridades e diferenças dos dois métodos supracitados. 
Este artigo procura contribuir para a difusão dos métodos de Análise Fundamentalista e Técnica no cenário acadêmico e na produção do conhecimento, pois há uma lacuna em relação aos estudos da área de análise de investimentos nestes meios, a partir da importância de tais ferramentas para a melhoria das operações no mercado de capitais e no aumento da probabilidade de sucesso na comercialização dos ativos.

\section{REFERENCIAL TEÓRICO}

\subsection{Contexto Geral: O Mercado de Capitais}

O mercado de capitais se define como um espaço (imaginário) em que um grupo de instituição de capital aberto, despeja os seus valores imobiliários ou títulos na bolsa, que podem ser por meio de ações, debêntures ou notas promissórias. Com objetivo de capitalizar recursos de indivíduos poupadores (investidores) à agentes/instituições com déficits de investimentos ou até mesmo para capital de giro. Consequentemente, o mercado de capitais é um mecanismo de compartilhamento de valores mobiliários com intuito de viabilizar as operações das empresas e possibilitar maior liquidez a seus títulos e ativos (FORTUNA, 2013; e PINHEIRO, 2005).

De acordo com Assaf Neto (2011, p. 74) "O mercado de capitais assume papel dos mais relevantes no processo de desenvolvimento econômico. É o grande municiador de recursos permanentes para a economia, em virtude da ligação que efetua entre os que têm capacidade de poupança, ou seja, os investidores, e aqueles carentes de recursos de longo prazo, ou seja, que apresentam déficit de investimento".

O aparecimento do mercado de capitais se deu mediante as limitações do mercado de crédito, que não conseguiu suprir todas as necessidades produtivas das empresas. Necessidades estas que buscavam garantir uma quantidade apropriada de recursos financeiros alocados na instituição, com intuito de cumprir com os prazos, gastos e exigibilidade que eram responsabilidade das empresas. Deste modo, o mercado foi criado para atender as seguintes finalidades: atuar para o desenvolvimento econômico, ser um mecanismo de capitação de recursos para investimentos, estimular a consolidação da poupança privada e proporcionar a distribuição de maneira mais igualitária da riqueza na nação (PINHEIRO, 2005; e COPELAND et al, 2002).

É imperioso registrar que o mercado de capitais divide-se em duas vertentes, o primário e o secundário. O primeiro é o local onde as empresas (por meio de ações, debêntures e notas promissórias) e governo (obrigações da dívida pública) ofertam novos 
títulos e ações aos poupadores (investidores), por meio de um contrato com a data, precificação e rentabilidade do ativo estipulados, mediante ao acordo de ambas as partes, realizado no mercado de Balcão. Enquanto que o segundo, o mercado secundário, caracterizase por transferências sucessivas de titularidade das ações/títulos entre os investidores (FORTUNA, 2013).

Ambos os mercados (primário e secundário) oferecem vantagem para com os agentes e à sociedade. $\mathrm{O}$ mercado primário proporciona uma injeção de recursos no setor produtivo da economia e contribui para o desenvolvimento da nação, por meio de geração de emprego, melhora da infraestrutura e correção dos desiquilíbrio regionais (distribuição de renda/rendimentos). Em relação ao mercado secundário, este evidencia o valor de mercado das empresas e garante liquidez dos ativos negociados (FORTUNA, 2013; ASSAF NETO, 2011; e PINHEIRO, 2005).

$V i s-\grave{a}$-vis ao desenvolvimento e respectivas inovações do mercado de capitais, diversas melhorias são geradas e, além de afetar positivamente os setores produtivos da economia na capitação de recursos, este benefício se expande para todos os agentes operadores do mercado, instituições de capital aberto e sociedade como um todo. Deste modo, para auxiliar na tomada de decisão dos investidores neste mercado cada vez mais competitivo e complexo, deu-se origem as análises Fundamentalistas e Técnicas.

A Análise Fundamentalista adota a hipótese da existência de um valor intrínseco em cada ação, com base nos resultados apurados pela empresa emitente, considerando uma gama de variáveis internas e externas para avaliar a situação financeira da empresa. Enquanto que a Análise Técnica/Gráfica dedica-se a formar projeções sobre o comportamento das ações a partir de padrões observado no desempenho passado do mercado e utiliza-se de cálculos matemáticos e estatísticos para efetivar sua análise. Nos próximos tópicos serão abordadas estas ferramentas (Fundamentalista e Técnica) com maior propriedade e detalhamento.

\subsection{Análise Fundamentalista}

A Análise Fundamentalista é uma das ferramentas utilizadas para maximizar os acertos dos investidores no mercado financeiro de ações com o intuito de avaliar qual seria o valor inerente de um ativo. Com este mecanismo, os investidores comparam o preço vigente no mercado e determinam a compra e venda do ativo, classificando com subvalorizado ou sobrevalorizado, respectivamente (VILLASCHI et al, 2011). Além disso, o preço também pode ser considerado como justo, ou seja, o preço encontrado pelo ativo assemelha-se ao empregado no mercado. Por tanto, a análise Fundamentalista define qual o ativo deve ser 
comprado ou vendido, e avalia os grandes movimentos em um período amplo (médio e longo prazo) (ARAÚJO E MAIA, 2011). Como bem define Penman (2004, p.3): “Underlying value is sometimes referred to as fundamental value, and the analysis of information about fundamental value is referred to as fundamental analysis".

A ferramenta Fundamentalista resume-se em um estudo da situação financeira das empresas e de suas expectativas futuras, buscando analisar o potencial de crescimento dos lucros esperados, que podem se refletir na valorização da ação no decorrer dos períodos vindouros. Esta análise tem como princípio avaliar o reflexo dos preços dos ativos em relação ao valor real das empresas, no qual pode ser verificado por meio das projeções e expectativas das empresas. Deste modo, esta ferramenta objetiva analisar e evitar preços incoerentes dos ativos em relação ao valor intrínseco de mercado (PIOTROSKI apud GALDI, 2008; BEIRUTH et al, 2007; e BODIE, KANE e MARCUS, 2001)

Assim sendo, o método Fundamentalista busca avaliar o valor intrínseco de uma carteira de ações, com objetivo de encontrar o preço justo que pode ser compreendido como valor real deste ativo no mercado. Esta ferramenta baseia-se na situação financeira das empresas, em suas devidas expectativas de crescimento e rendimento, na análise de seus riscos e em outros indicadores. Logo, esta técnica de tomada de decisão define qual será o ativo a ser adquirido ou abandonado pelo investidor. $\mathrm{O}$ analista fundamentalista busca centralizar os seus estudos no comportamento econômico e financeiro das empresas, como também em comparar as empresas de um mesmo setor (segmento), observando a conjuntura econômica e politica atual (LAGIOIA, 2007; BEIRUTH et al, 2007; e DAMODARAN, 2002).

Neste artigo foram calculados os indicadores de estrutura de capital (participação de capital de terceiros, composição do endividamento, imobilização do patrimônio líquido e dos recursos não correntes), de liquidez (liquidez geral, corrente, seca e imediata), indicadores de rentabilidade (margem líquida e ROI - retorno sobre o investimento), além dos indicadores de mercado (lucro por ação e rendimento de dividendos - "dividend yield").

\subsection{Análise Técnica}

A Análise Técnica se baseia em três princípios que auxiliam no desenvolvimento das demais técnicas. O primeiro diz que o preço desconta tudo e o mais importante nisto é saber como será o movimento do preço para saber o "start" de compra/venda do ativo. Portanto, o preço pode armazenar nos gráficos vários fatores como, por exemplo, econômicos e políticos, 
mas para o autor todos estes dados estarão contidos no valor/preço da ação. Já o segundo princípio, relata que o preço age por tendência, isto é, o preço acompanha as decisões dos acionistas, tanto positiva, quanto negativamente, ou vice-versa, originando as tendências ascendentes e descendentes. O terceiro princípio abrange a parte emocional dos agentes que são movidos por perdas e ganhos, sendo representados por padrões que vão se repetindo no decorrer do tempo e quanto mais representados estes padrões, mais previsível é o mercado (PINHEIRO, 2005; CHAVES e ROCHA, 2004; e NORONHA, 1995).

A Análise Gráfica é um seguimento de grande importância no estudo da Análise Técnica, pois esta ferramenta proporciona uma análise sobre figuras e formas que implicam na constituição de tendências e de período de reversões sob uma ação. Esta técnica possibilita observar o momento exato para compra/venda de ações da empresa em análise. Existe uma gama de gráficos a serem utilizados pelo analista com intuito de avaliar um ativo financeiro, são estes: gráfico de volume, gráfico de linha, gráfico de barra, gráfico de candlesticks. Estes gráficos orientam sobre a tendência, mostrando a direção em que o mercado se encontra, sendo esta: de baixa, de alta e lateral (lateralizada). As tendências se dividem em dois seguimentos: as de continuidade e de reversão. As formas de continuidade mantêm a tendência no mesmo sentido que se encontrar, diferente das formas de reversão que se observa uma mudança de direção da tendência. (VIDOTTO et al, 2009).

A Análise Técnica se difere da Gráfica, pois a primeira utiliza cálculos estatísticos e matemáticos para realizar a sua análise e utiliza dos gráficos como complemento e confirmação de seus estudos. Enquanto que o segundo método utiliza-se de linhas tendências, não compactua com a utilização dos cálculos estatísticos e embasa suas analises na avaliação dos gráficos de preços (ou cotações) (YANG e SATCHELL, 2003).

Em suma, a Análise técnica estuda o comportamento dos preços, usando em seu arcabouço teórico a matemática e os preços históricos. Empregando em sua linha de pesquisa os mecanismos de médias móveis, bandas de Bollinger, convergência e divergência (MACD), índice de força relativa (IFR) e dentre outros. Já a Análise Grafista, busca compreender os movimentos dos investidores e como estes se comportam (psicologia do mercado). E para isso este estudo utiliza-se de diagnóstico de tendências, gráficos e figuras, volume financeiro, e suporte/ resistência.

Dessa forma, verifica-se que a Análise Fundamentalista adota a hipótese da existência de um valor intrínseco em cada ação, com base nos resultados apurados pela empresa emitente, considerando uma gama de variáveis internas e externas para avaliar a situação 
financeira da empresa. Já Análise Técnica/Gráfica dedica-se a formar projeções sobre o comportamento das ações a partir de padrões observado no desempenho passado do mercado, utilizando-se de cálculos matemáticos e estatísticos para efetivar sua análise.

\section{METODOLOGIA}

Realizou-se uma pesquisa quantitativa a partir de dados secundários, metodologia estatística para a mensuração dos resultados, formação de uniformidades e testes. Conforme Fachin (2003), o método quantitativo de análise tem como objetivos empíricos exibir e tratar os dados, empregando conceitos numéricos com intuito de avaliar hipóteses, utilizando-se de análises estatísticas, por meio do processo de amostragem.

Trata-se de uma pesquisa descritiva, pois busca apresentar particularidades de determinada população ou acontecimento ou correlação/discrepância entre as variáveis (GIL, 1991). Foram utilizados dados secundários coletados nos demonstrativos financeiros das empresas e nas cotações diárias, conforme o software da ADVFN e Economática; de informações publicadas em livros, jornais, revistas e sites na internet, utilizando o software Excel para tabulação dos dados e cálculo de indicadores fundamentalistas e estatísticos. As empresas pesquisadas, por possuírem capital aberto em Bolsa de Valores e inúmeros shareholders (acionistas), têm seus dados e informações disponibilizados ao mercado.

A seleção das empresas foi feita com base no volume financeiro negociado na BM\&F Bovespa no ano de 2012. A partir dessa amostra definida intencionalmente, segundo as partes que a compõem, propôs-se analisar somente cinco sociedades anônimas com papéis negociados no Brasil. Os ativos de análise utilizados foram as ações das companhias conforme quadro1; as cotações diárias foram obtidas através da ADVFN, que disponibiliza os dados e gráficos em tempo real.

Quadro 1 - Ações

\begin{tabular}{|c|c|}
\hline Código & Empresa \\
\hline OGXP3 & OGX Petroleo ON \\
\hline PETR4 & PETROBRAS PN \\
\hline VALE5 & VALE PN \\
\hline VALE3 & VALE ON \\
\hline PETR3 & PETROBRAS ON \\
\hline BVMF3 & BMF BOVESPA ON \\
\hline PDGR3 & PDG REALT ON \\
\hline
\end{tabular}

Fonte: Elaborado pelo autor, 2014.

Para definição da amostra, trabalhou-se com as dez ações de maior volume transacionado na BM\&F Bovespa, sendo que três dessas ações foram eliminadas da amostra 
por serem de instituições financeiras, que possuem demonstrações financeiras específicas do segmento bancário. Assim, foram analisadas apenas as 7 ações com maior volume transacionado na BM\&F Bovespa no ano de 2012 e utilizadas as cotações diárias no período entre $1^{\circ}$ de janeiro e 31 de dezembro, como série temporal.

As técnicas de análise utilizadas foram a Técnica e a Fundamentalista, sendo que esta adota a hipótese da existência de um valor intrínseco em cada ação, com base nos resultados apurados pela empresa emitente, considerando uma gama de variáveis internas e externas para avaliar a situação financeira da empresa, conforme Quadro 2:

\section{Quadro 2 - Índices Fundamentalistas}

\begin{tabular}{|c|c|c|}
\hline Liquidez Corrente (LC) & $\begin{array}{c}\text { Ativo circulante } \\
\text { Passivo circulante }\end{array}$ & $\begin{array}{c}\text { Quanto à empresa possui de ativo circulante para } \\
\text { cada } \mathrm{R} \$ 1,00 \text { de passivo de curto prazo. }\end{array}$ \\
\hline Liquidez Seca (LS) & $\frac{\text { Ativo Circulante }- \text { Estoques }}{\text { Passivo Circulante }}$ & $\begin{array}{l}\text { Quanto à empresa possui de ativo ativo líquido } \\
\text { para cada } \mathrm{R} \$ 1,00 \text { de passivo circulante. }\end{array}$ \\
\hline Liquidez Imediata (LI) & $\begin{array}{c}\text { Disponibilidades } \\
\text { Passivo Circulante }\end{array}$ & $\begin{array}{l}\text { Quanto à empresa possui de caixa e equivalentes } \\
\text { de caixa para cada } R \$ 1,00 \text { de passivo circulante. }\end{array}$ \\
\hline \multicolumn{3}{|c|}{ ESTRUTURA } \\
\hline $\begin{array}{l}\text { Participação Capital de } \\
\text { Terceiros (Part K3) } \\
\end{array}$ & $\begin{array}{c}\text { Passivo Circulante }+ \text { Passivo Não Circulante } \\
\text { Patrimônio Líquido }\end{array}$ & $\begin{array}{c}\text { Quanto à empresa pegou de capital de terceiros } \\
\text { para cada } R \$ 1,00 \text { de capital próprio. }\end{array}$ \\
\hline $\begin{array}{c}\text { Composição do } \\
\text { Endividamento (Comp. End) }\end{array}$ & $\frac{\text { Passivo circulante }}{\text { Passivo Circulante }+ \text { Passivo Não Circulante }}$ & $\begin{array}{l}\text { Qual o percentual da dívida total (passivo) é de } \\
\text { curto prazo (circulante). }\end{array}$ \\
\hline $\begin{array}{c}\text { Imbolização do Patrimônio } \\
\text { Líquido (IPL) }\end{array}$ & $\begin{array}{l}\text { Ativo Permanente* } \\
\text { Patrimônio Líquido }\end{array}$ & $\begin{array}{l}\text { Qual a proporção de recursos próprios (PL) a } \\
\text { empresa investiu em ativos permanentes. }\end{array}$ \\
\hline $\begin{array}{c}\text { Imobilização de Recursos } \\
\text { Não Correntes (IRNC) } \\
\end{array}$ & $\begin{array}{l}\text { Disponibilidades } \\
\text { Passivo Circulante }\end{array}$ & $\begin{array}{l}\text { Qual a proporção de recursos não correntes (PL+ } \\
\text { PNC) a empresa investiu em ativos permanentes. }\end{array}$ \\
\hline \multicolumn{3}{|c|}{ RENTABILIDADE } \\
\hline Margem Líquida (ML) & $\begin{array}{c}\text { Lucro Líquido } \\
\text { Vendas Líquidas }\end{array}$ & $\begin{array}{l}\text { Quanto a empresa obtém de lucro líquido para } \\
\text { cada } R \$ 1,00 \text { vendido. }\end{array}$ \\
\hline $\begin{array}{l}\text { ROI (Retorno sobre } \\
\text { Inves timentos) }\end{array}$ & $\frac{\text { Lucro Líquido }}{\text { Ativo Médio }}$ & $\begin{array}{l}\text { Quanto a empresa obtém de lucro líquido para } \\
\text { cada } R \$ 1,00 \text { investimento total. }\end{array}$ \\
\hline \multicolumn{3}{|c|}{ MERCADO } \\
\hline Lucro por Ação (LPA) & $\frac{\text { Lucro Líquido }}{\text { Número de Ações Emitidas }}$ & $\begin{array}{l}\text { O ganho potencial (e não efetivo) de cada ação, já } \\
\text { que nem sempre todo lucro é distribuído. }\end{array}$ \\
\hline $\begin{array}{c}\text { Rendimento de Dividendos } \\
\text { (Dividend Yield) (RDA) }\end{array}$ & $\begin{array}{l}\text { Dividendos pagos no Período } \\
\text { Número de Ações Beneficiadas }\end{array}$ & $\begin{array}{c}\text { Avalia a relação entre o montante de dividendos } \\
\text { pagos e o número de ações beneficiadas. }\end{array}$ \\
\hline
\end{tabular}

* Nomenclatura utilizada para designar as seguintes contas do Ativo: Investimentos, Imobilizado e Intangíveis.

Já a Análise Técnica dedica-se a formar projeções sobre o comportamento das ações a partir de padrões observados no desempenho passado do mercado, utilizando-se de cálculos matemáticos e estatísticos para efetivar sua análise, de acordo com Quadro 3 a seguir: 


\section{Revista de Administração e Negócios da Amazônia, V.7, n.2, mai/ago. 2015 \\ ISSN: 2176-8366 D0I: 10.18361/2176-8366/rara.v7n2p39-63}

Quadro 3 - Indicadores de Análise Téenica

\begin{tabular}{|c|c|c|}
\hline Imagem & Ferramenta & Informação \\
\hline Anth $V^{H}$ & Figura Bandeira e Fâmula & $\begin{array}{c}\text { As Bandeiras e Flâmulas são figuras que confirmam a } \\
\text { tendência já existente e compõe uma das formas mais } \\
\text { clássicas utilizadas pelos analistas gráficos. Estas são } \\
\text { consideradas correções de preços que se desenvolvem após } \\
\text { uma oscilação acentuada da cotação. }\end{array}$ \\
\hline Fine $-4=2$ & Figuras ombro-cabeça-ombro & $\begin{array}{c}\text { A cabeça encontra-se em um nível mais elevado que os } \\
\text { ombros e este padrão também é encontrado na forma } \\
\text { invertida quando marcar a reversão de tendência de baixa } \\
\text { para a alta. O acréscimo no volume confirma o momento do } \\
\text { rompimento da linha de pescoço. }\end{array}$ \\
\hline & $\begin{array}{c}\text { Linha de tendência (exemplo } \\
\text { de tendência de alta) }\end{array}$ & $\begin{array}{c}\text { Tendência de alta: topos e fundos Ascendenetes; } \\
\text { Tendência de Baixa: topos e Fundos descendentes; } \\
\text { Tendência Neutra: topos e fundos lateralizados } \\
\text { irregularmente. }\end{array}$ \\
\hline 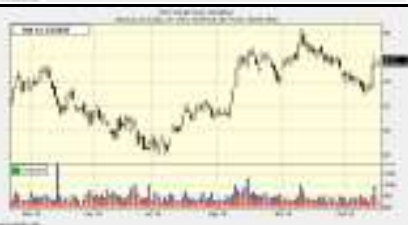 & O volume Financeiro & $\begin{array}{c}\text { Este indica a quantidade total das transações monetárias que } \\
\text { foram realizadas no dado período de análise, que na maioria } \\
\text { das vezes é representado por um gráfico de barras a partir do } \\
\text { gráfico de preços. }\end{array}$ \\
\hline & Suporte e Resistência & $\begin{array}{c}\text { A regra principal de negociação com a ferramenta de suporte } \\
\text { e resistência é comprar no suporte e vender na resistência. } \\
\text { Para observar a força para a utilização da ferramenta, analisa- } \\
\text { se mediante a quantidade de vezes em que o mercado irá } \\
\text { "atacar" a linha de suporte/resistência e recuar. }\end{array}$ \\
\hline & Bandas de Bollinger & $\begin{array}{c}\text { As Bandas de Bollinger se pauta na estatística em que } 95 \% \\
\text { dos preços oscilam no intervalo estabelecido pelo desvio } \\
\text { padrão e estas oscilações podem gerar ganhos aos investidos } \\
\text { em dois momentos distintos (MMS 20,Dp 2). }\end{array}$ \\
\hline 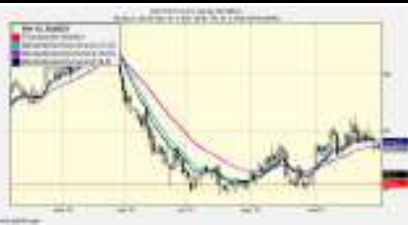 & $\begin{array}{c}\text { Médias Móveis Simples e } \\
\text { MACD }\end{array}$ & $\begin{array}{l}\text { A média móvel simples (MMS) é obtida pela média } \\
\text { aritmética de } \mathrm{n} \text { cotações em decorrência de n-períodos. As } \\
\text { médias móveis de curto e longo prazo e a alinha de sinal em } \\
\text { conjunto, geram um indicador de Convergência-Divergência } \\
\text { da média móvel (MACD) que sinalizam a compra/venda. }\end{array}$ \\
\hline 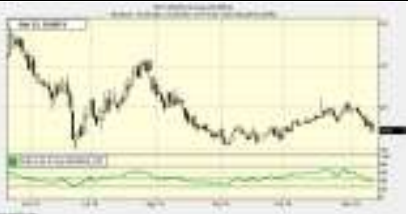 & Índice de força relativa & $\begin{array}{l}\text { O IFR é um oscilador que regula a aceleração nas mudanças } \\
\text { dos preços de um determinado ativo, prevendo possíveis } \\
\text { reversões, possibilita notar, ao acompanhá-lo, o } \\
\text { abrandamento da tendência e sua possível reversão. }\end{array}$ \\
\hline
\end{tabular}

Fonte: Elaborado pelo autor, 2014.

Assim, com exceção das figuras gráficas, foram utilizadas diversas fórmulas matemáticas e estatísticas para cálculos de ordem técnica. Para o Índice de Força Relativa (IFR) - um oscilador que regula a aceleração nas mudanças dos preços de um determinado 
ativo, prevendo possíveis reversões, possibilitando notar, ao acompanhá-lo, o abrandamento da tendência e sua possível reversão - utilizou-se a seguinte fórmula:

$$
I F R=100-(100 / 1+(\mathrm{z} / \mathrm{w}))
$$

Sendo:

$\mathrm{z}=$ média dos dias de alta do período e $\mathrm{w}=$ média dos dias de baixa do período

Este índice varia entre 0 e $100 \%$, as estimações acima de $80 \%$ são possíveis mercados sobre-comprados, podendo ocorrer um risco de queda na tendência, ficando abaixo deste valor. E quando o índice se encontra em um valor abaixo de $20 \%$, é sugerível como mercado sobre-vendido, em que haverá uma pressão de alta quando este índice superar a casa dos $20 \%$. Esse índice (IFR) é normalmente calculado nos períodos de 9,14 e 25 , mas não há um padrão certo a ser tomado, pois determinados períodos servem melhor para um dado mercado. Portanto, deve-se testar o que melhor adaptará ao papel e índices que estão sendo utilizados pelo investidor.

Em seguida, foi calculada as médias móveis - ferramenta simplistas para análise de ativos, cuja finalidade consiste em amortecer os ruídos das oscilações dos preços no curto prazo, buscando facilitar e identificar a análise da tendência - para 5 e 20 períodos das empresas analisadas. Desse modo, para avaliar o sinal de compra/venda é preciso que o valor destas médias se cruze. Quando os valores das médias se cruzarem e a média de 5 períodos obtiver um valor maior que a média de 20 períodos, confirma-se o sinal de compra. Se, em caso contrário, a média de 5 períodos obtiver um valor menor do que a média de 20 períodos, consequentemente ocorrerá uma aprovação de venda.

A fórmula utilizada para o cálculo dessa ferramenta é a seguinte:

$$
M M S n=(\mathrm{V} 1+\mathrm{V} 2+\ldots+\mathrm{Vn}) / \mathrm{n}
$$

Onde:

$\mathrm{n}=$ número de períodos e $\mathrm{V}=$ Valor

Após calcular as médias móveis foram determinados os seguintes indicadores de estatística descritiva: o retorno médio das cotações - que compreende a média do somatório dos retornos diários das ações $(\mathrm{R}=\ln \mathrm{x} / \mathrm{y}$, onde $\mathrm{x}$ representa a cotação no dia atual e y a ação do dia anterior) e a variância $\left(\sum(\mathrm{xi}-\text { Média })^{2} /(\mathrm{n}-1)\right)$ das mesmas. Ademais, para auxiliar na análise, foram demarcadas as cotações mínimas e máximas de cada empresa. 


\section{APRESENTAÇÃO E ANÁLISE DE RESULTADOS}

No âmbito dos Índices Fundamentalistas foram observados os seguintes valores:

Quadro 4 - Indicadores de Estrutura de Capital

\begin{tabular}{|c|c|c|c|c|c|}
\hline $\begin{array}{c}\text { Indicadores de Estrutura de } \\
\text { Capital }\end{array}$ & $\begin{array}{c}\text { OGX } \\
\text { PETROLEO }\end{array}$ & VALE & PETROBRAS & $\begin{array}{c}\text { PDG } \\
\text { REALT }\end{array}$ & $\begin{array}{c}\text { BMF } \\
\text { BOVESPA }\end{array}$ \\
\hline $\begin{array}{c}\text { Índice de Participação de } \\
\text { capital de terceiros }\end{array}$ & 1,21 & 0,71 & 0,97 & 2,19 & 0,23 \\
\hline $\begin{array}{c}\text { Índice de Composição de } \\
\text { Endividamento }\end{array}$ & 0,13 & 0,23 & 0,21 & 0,41 & 0,31 \\
\hline $\begin{array}{c}\text { Índice de Imobilização do } \\
\text { Patrimônio Liquido }\end{array}$ & 1,56 & 1,32 & 1,49 & 0,19 & 1,03 \\
\hline $\begin{array}{c}\text { Índice de Imobilização dos } \\
\text { Recursos Não Correntes }\end{array}$ & 0,76 & 0,85 & 0,85 & 0,08 & 0,89 \\
\hline
\end{tabular}

Fonte: Economática, elaborado pelo autor, 2014.

Em outra vertente analítica, encontram-se os Indicadores de Liquidez, responsáveis por comprovar a capacidade da empresa em cumprir com os seus compromissos. Dessa feita, quanto maior os indicadores apresentados, melhor para a firma. Seguem no Quadro 5 os resultados alcançados com a aplicação das equações de liquidez:

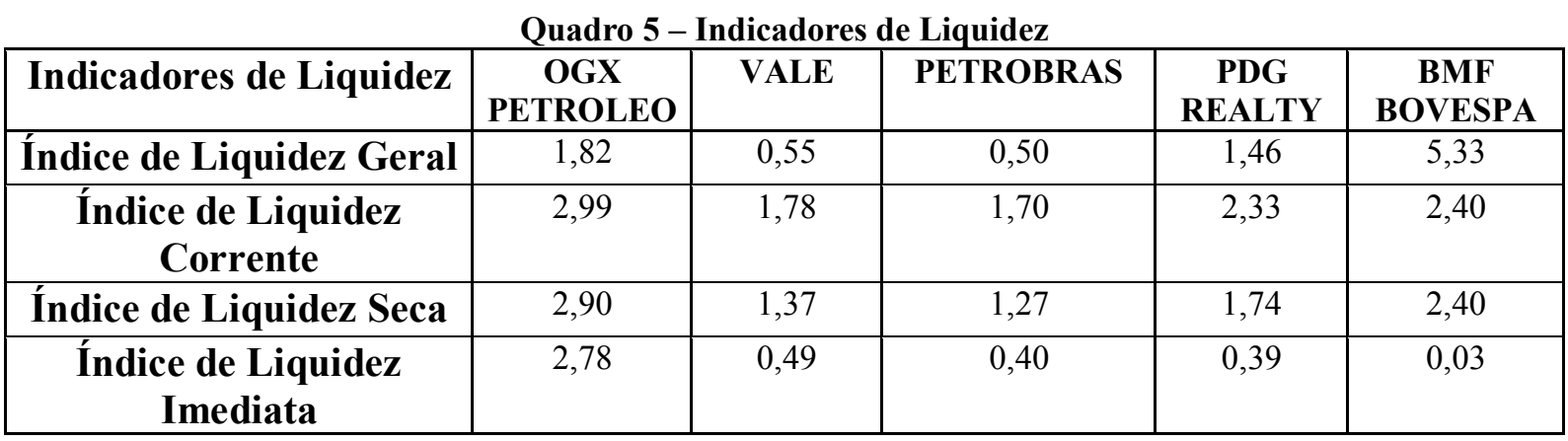

Fonte: Economática, elaborado pelo autor, 2014

Os Indicadores de Rentabilidade buscam compreender a capacidade de geração de resultados das empresas. Este grupo de indicadores informa a lucratividade da empresa e a rentabilidade desta e de terceiros. Aplicados dois importantes índices à amostra de dados, especificamente Margem Líquida e Retorno sobre Investimento (ROI), têm-se os resultados apresentados no Quadro 6:

Quadro 6 - Indicadores de Rentabilidade

\begin{tabular}{|c|c|c|c|c|c|}
\hline $\begin{array}{c}\text { Indicadores de } \\
\text { Rentabilidade }\end{array}$ & $\begin{array}{c}\text { OGX } \\
\text { PETROLEO }\end{array}$ & VALE & PETROBRAS & $\begin{array}{c}\text { PDG } \\
\text { REALTY }\end{array}$ & $\begin{array}{c}\text { BMF } \\
\text { BOVESPA }\end{array}$ \\
\hline Margem Líquida & $-3,50$ & 0,10 & 0,07 & $-0,50$ & 2,43 \\
\hline ROI & $-0,82$ & 0,62 & 0,54 & 3,57 & 4,37 \\
\hline
\end{tabular}

Fonte: Economática, elaborado pelo autor, 2014. 
$\mathrm{Na}$ esfera dos Indicadores de Mercado, responsáveis por demonstrar o Lucro por Ação, o percentual de participação dos acionistas neste lucro auferido e o retorno obtido pelos sócios, por meio de distribuição de dividendos e juros por capital próprio, foi utilizada uma abordagem dual: Lucro por Ação (LPA) e dividend yield, respectivamente, como bem apresenta o Quadro 7 disposto abaixo:

Quadro 7 - Indicadores de Mercado

\begin{tabular}{|c|c|c|c|c|c|}
\hline $\begin{array}{c}\text { Indicadores de } \\
\text { Mercado }\end{array}$ & $\begin{array}{c}\text { OGX } \\
\text { PETROLEO }\end{array}$ & VALE & PETROBRAS & $\begin{array}{c}\text { PDG } \\
\text { REALTY }\end{array}$ & $\begin{array}{c}\text { BMF } \\
\text { BOVESPA }\end{array}$ \\
\hline Lucro por Ação & $-0,35$ & 1,72 & 1,61 & $-1,63$ & 0,54 \\
\hline $\begin{array}{c}\text { Rendimento de } \\
\text { Dividendos }\end{array}$ & 0,00 & 0,06 & 0,02 & 0,00 & 0,04 \\
\hline
\end{tabular}

Fonte: Economática, elaborado pelo autor, 2014

Visto os indicadores fundamentalistas, serão abordadas as ferramentas utilizadas pela análise técnica/grafista e os resultados alcançados. No primeiro momento foram discutidos os gráficos de cada ativo que compõe a amostra da pesquisa, com base nas cotações diárias do período de janeiro a dezembro de 2012, conforme Gráfico 1:

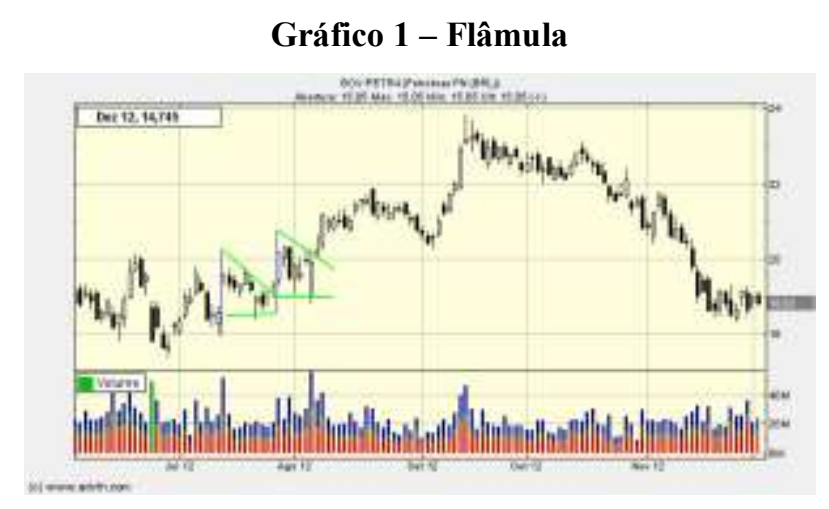

Fonte: Adaptado de ADVFN, 2013.

A formação da flâmula apresenta uma continuação da tendência de curto prazo, ratificando o prolongamento do movimento. No gráfico, ao final do primeiro trimestre (julho), encontra-se o mastro da flâmula. Logo em seguida, o volume financeiro contrai quando se configura o corpo da flâmula e, no ponto de fuga no final da figura, o volume demonstra um avanço significativo confirmando a formação da figura e a projeção dos preços. Tem-se que a altura do mastro foi de $\$ 1,74$, valor utilizado para a projeção do preço. Assim, após romper a linha de resistência da flâmula quando valia $\$ 18,50$, a ação chegou à cotação de $\$ 20,40$, confirmando a projeção do preço que reflete a altura da figura. Nesse cenário, os investidores 
devem comprar a ação assim que a projeção é confirmada pelo rompimento da linha de resistência e também pelo volume.

No Gráfico 2 da Vale PNA (VALE5), apresentou-se uma figura de reversão de nome Ombro-Cabeça-Ombro no período entre junho e julho de 2012:

Gráfico 2 - Ombro-Cabeça-Ombro (O.C.O)

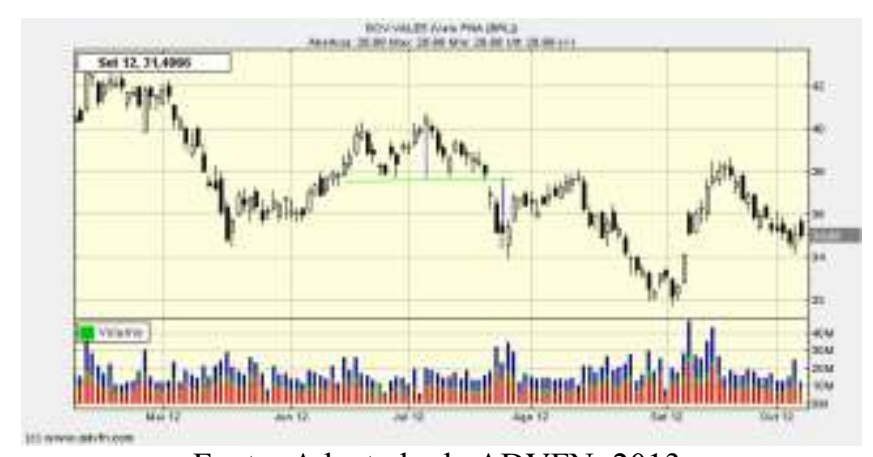

Fonte: Adaptado de ADVFN, 2013.

Observa-se que a altura da linha de pescoço (suporte) até a cabeça foi de $\$ 2,16$, ou seja, a previsão é de que depois de romper a linha de suporte a ação atingisse este valor, o que veio a ocorrer, confirmando a previsão de preço determinada. Dessa maneira, após romper a linha de pescoço e a ocorrência de um gap, o valor da ação deveria chegar $\$ 35,12$, valor da ação na linha de suporte menos a altura do pescoço $(\$ 37,81$ menos $\$ 2,16)$. A previsão foi confirmada e assim que a linha de suporte foi rompida; o indicado aos investidores é vender suas ações a fim de reduzir as perdas.

No Gráfico 3 visualiza-se o desempenho da OGX Petróleo (OGXP3), realizando uma tendência de baixa no período de março a julho de 2012 .

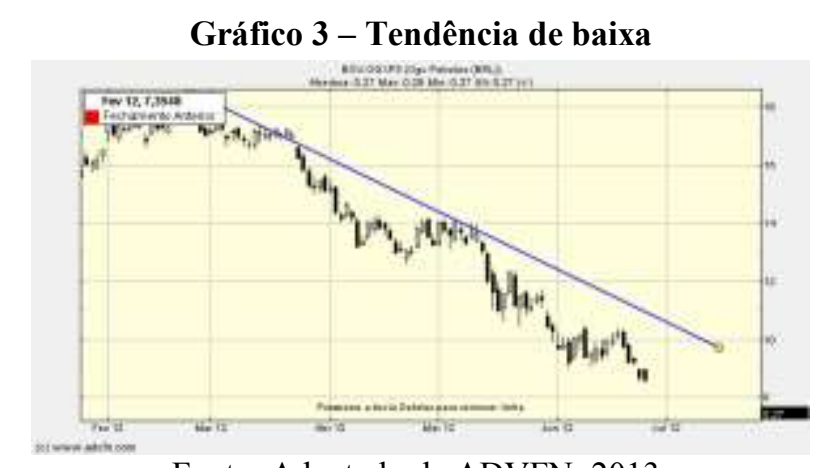

Fonte: Adaptado de ADVFN, 2013.

Verifica-se uma tendência de baixa, pois os topos e fundos apresentam uma trajetória descendente. $\mathrm{O}$ valor no início da queda foi de $\$ 18,08$, atingindo ao final da tendência o preço de $\$ 8,60$, portanto, houve uma perda de $\$ 9,58$. 
O Gráfico 4 apresenta-se uma figura de suporte e resistência:

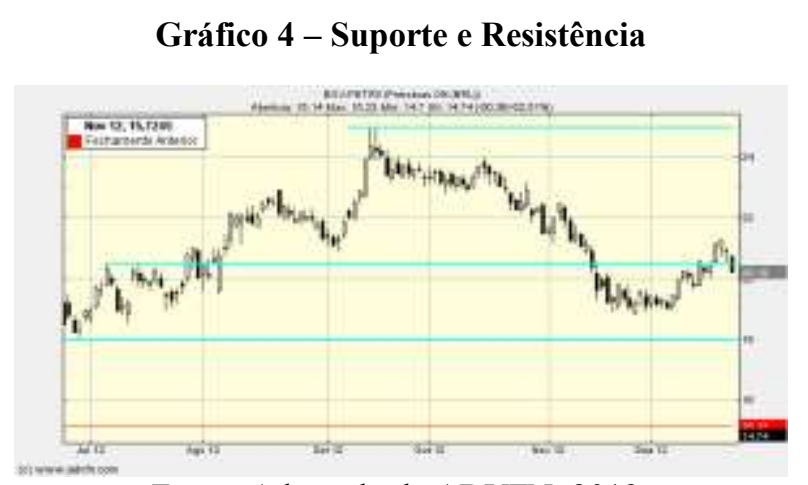

Fonte: Adaptado de ADVFN, 2013.

No gráfico acima, no mês de julho, o mercado testa a linha de resistência duas vezes até rompê-la, e nesse momento será a ocasião para que o acionista compre o seu lote de ações. Posteriormente o mercado testa apenas uma vez a nova resistência e ocorre uma queda na cotação do ativo. Portanto essa ferramenta poderia ser complementada com outro método de análise para atingir um maior êxito na operação.

No Gráfico 5, relativo à BM\&FBovespa (BVMF3), contém as Bandas de Bollinger no período de maio a outubro de 2012.

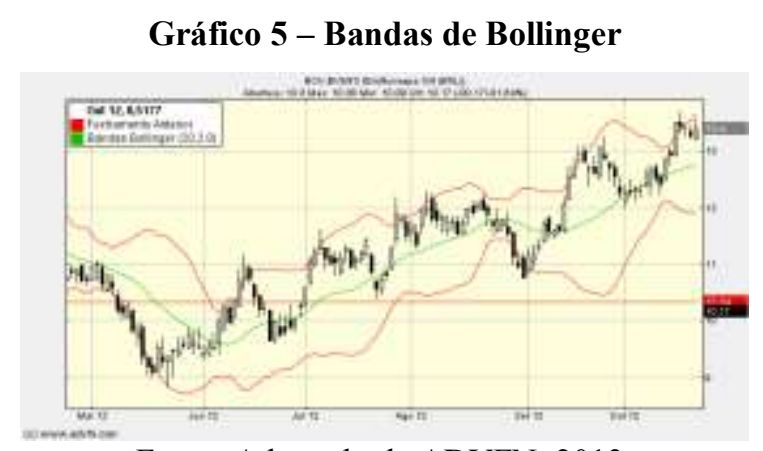

Fonte: Adaptado de ADVFN, 2013.

Observa-se que, no mês de maio, o mercado estava rompendo a banda inferior e, portanto, houve uma força realizada pelos compradores para que a cotação retoma-se ao equilibro próximo da média. Já nos meses de junho a agosto ocorreu o contrário: o mercado estava rompendo para cima a margem superior originando-se uma força vendedora neste período, oscilando entre a média e a margem superior das bandas. Somente no final de agosto e início de setembro ocorreu outro rompimento da banda inferior, que logo no meio do mês de setembro voltou à média. Já no último trimestre (setembro) até o final de outubro ocorreram dois rompimentos da banda superior, oscilando entre a média do período. Em suma, quando o preço da ação rompe a banda inferior, são geradas forças compradoras e por isso será o 
melhor momento de compra deste ativo. De forma inversa, quando se rompe a banda superior, é o melhor momento de venda, pois serão geradas forças de venda e o ativo irá desvalorizar-se até chegar à média do período.

No Gráfico 6, referente à Petrobras PN (PETR4), é analisado o IFR no período de junho a dezembro do ano de 2012.

\section{Gráfico 6 - Índice de Força Relativa (IFR)}

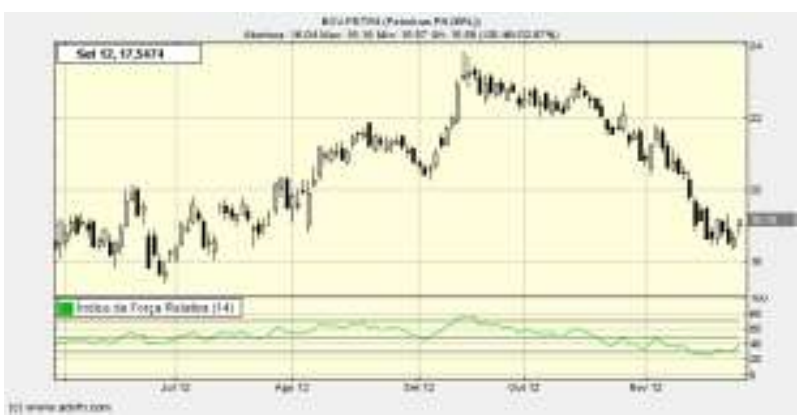

Fonte: Adaptado de ADVFN, 2013.

Verifica-se que o IFR oscila entre $0 \%$ e $100 \%$ e quando a linha verde ultrapassa a margem de $70 \%$ o mercado está sobre-comprado e possivelmente haverá uma queda de tendência e cotação do ativo. Foi no início do segundo bimestre (setembro). E no final do mês de novembro ocorreu o inverso, quando o índice toca a margem inferior com valor de $20 \%$ (sobre-vendido), ocorrendo uma alta na tendência e nos preços.

Nos quadros $8,9,10,11,12,13$ e 14, o enfoque recai sobre as médias móveis de 5 e 20 períodos das empresas analisadas, que apresentaram os seguintes resultados:

Quadro 8 - Médias Móveis da OGX Petróleo ON

\begin{tabular}{|c|c|c|c|c|c|c|c|c|c|}
\hline \multicolumn{10}{|c|}{ OGX Petroleo ON } \\
\hline Data & Abertura & Máx & Mín & Fechamento & Volume & MM5 & MM20 & Sinal & Resultado \\
\hline $1 / 10 / 2012$ & 6,2 & 6,28 & 5,99 & 5,99 & 28636600 & 6,40 & 6,41 & Venda & $4,17 \%$ \\
\hline $3 / 8 / 2012$ & 5,75 & 5,91 & 5,71 & 5,75 & 22835200 & 5,71 & 5,64 & Compra & $0 \%$ \\
\hline $5 / 3 / 2012$ & 17,35 & 17,39 & 17,07 & 17,26 & 10224300 & 17,29 & 17,43 & Venda & $27,38 \%$ \\
\hline $6 / 1 / 2012$ & 13,65 & 13,92 & 13,45 & 13,55 & 15031300 & 13,77 & 13,72 & Compra & $0 \%$ \\
\hline \multicolumn{9}{|c|}{ Total } & $32 \%$ \\
\hline
\end{tabular}

Fonte: Economática, elaborado pelo autor, 2014.

As médias móveis calculadas indicam as situações de compra nos dias 06/01 e 03/08, enquanto sinalizam a venda nos dias 05/03 e 01/10 para a OGX. Em suma, as médias móveis de curto e longo prazo e a linha de sinal em conjunto geram um indicador de ConvergênciaDivergência da média móvel (MACD) que sinalizam a compra/venda. Os sinais se dão respectivamente, quando as curvas de curto e longo prazo cotam a curva de sinal no sentido ascendente indica sinal de compra, e quando as curvas de curto prazo e de longo prazo ultrapassam a linha de sinal no sentido descendente, teremos um sinal de venda deste ativo neste momento, o mesmo acontece para os demais ativos financeiros (vide quadros a seguir): 
Quadro 9 - Médias Móveis da Petrobras PN

\begin{tabular}{|c|c|c|c|c|c|c|c|c|c|}
\hline \multicolumn{10}{|c|}{ Petrobras PN } \\
\hline Data & Abertura & Máx & Mín & Fechamento & Volume & MM5 & MM20 & Sinal & Resultado \\
\hline $6 / 1 / 2012$ & 22,47 & 22,58 & 22,25 & 22,33 & 13941000 & 22,10 & 22,09 & Compra & $0 \%$ \\
\hline $16 / 2 / 2012$ & 22,95 & 23,93 & 22,83 & 23,88 & 36725000 & 24,15 & 24,55 & Venda & $6,94 \%$ \\
\hline $2 / 3 / 2012$ & 24,94 & 25,3 & 24,86 & 25,3 & 20122000 & 24,47 & 24,40 & Compra & $0 \%$ \\
\hline $12 / 3 / 2012$ & 23,55 & 23,76 & 23,36 & 23,43 & 13888100 & 24,02 & 24,21 & Venda & $-7,39 \%$ \\
\hline $20 / 3 / 2012$ & 24,01 & 24,31 & 23,97 & 24,27 & 17585500 & 24,25 & 24,24 & Compra & $0 \%$ \\
\hline $23 / 3 / 2012$ & 23,93 & 24,1 & 23,67 & 23,7 & 16054200 & 24,15 & 24,26 & Venda & $-2,35 \%$ \\
\hline $21 / 6 / 2012$ & 20,01 & 20,07 & 19,27 & 19,27 & 27366300 & 19,03 & 18,91 & Compra & $0 \%$ \\
\hline $28 / 6 / 2012$ & 17,6 & 18 & 17,42 & 17,7 & 21382900 & 18,45 & 18,77 & Venda & $-8,15 \%$ \\
\hline $6 / 7 / 2012$ & 19,35 & 19,5 & 19,1 & 19,2 & 21172600 & 18,83 & 18,71 & Compra & $0 \%$ \\
\hline 4/9/2012 & 20,63 & 20,74 & 20,38 & 20,43 & 14057800 & 21,00 & 21,05 & Venda & $6,40 \%$ \\
\hline 13/9/2012 & 21,94 & 23,06 & 21,81 & 22,9 & 40030600 & 21,31 & 21,17 & Compra & $0 \%$ \\
\hline $5 / 10 / 2012$ & 22,68 & 22,68 & 22,2 & 22,25 & 14597000 & 22,46 & 22,52 & Venda & $-2,84 \%$ \\
\hline 19/10/2012 & 22,53 & 22,6 & 22,22 & 22,25 & 19987600 & 22,64 & 22,57 & Compra & $0 \%$ \\
\hline $23 / 10 / 2012$ & 21,94 & 21,97 & 21,5 & 21,67 & 25921300 & 22,44 & 22,50 & Venda & $-2,61 \%$ \\
\hline $12 / 12 / 2012$ & 19,93 & 20,05 & 19,68 & 19,85 & 34706800 & 19,26 & 19,16 & Compra & $0 \%$ \\
\hline \multicolumn{9}{|c|}{ Total } & $-10 \%$ \\
\hline
\end{tabular}

Fonte: Economática, elaborado pelo autor, 2014.

Nota-se, através das médias móveis representadas no Quadro 9 acima, sinalizações de compra e venda ao longo de todo o ano para as ações da Petrobrás PN. Vale destacar que nos meses de Agosto e Novembro não foi possível determinar sinais de compra ou venda, através deste instrumento de análise.

Quadro 10 - Médias Móveis da Vale PN

\begin{tabular}{|c|c|c|c|c|c|c|c|c|c|}
\hline \multicolumn{10}{|c|}{ Vale PNA } \\
\hline Data & Abertura & Máx & Mín & Fechamento & Volume & MM5 & MM20 & Sinal & Resultado \\
\hline $4 / 1 / 2012$ & 40,03 & 40,92 & 39,85 & 40,79 & 15518200 & 38,56 & 38,49 & Compra & $0 \%$ \\
\hline $20 / 2 / 2012$ & 41,99 & 41,99 & 41,99 & 41,99 & 0 & 42,61 & 42,64 & Venda & $2,94 \%$ \\
\hline $2 / 4 / 2012$ & 41,7 & 42,86 & 41,41 & 42,55 & 22896200 & 41,09 & 40,97 & Compra & $0 \%$ \\
\hline $10 / 4 / 2012$ & 40,6 & 40,67 & 39,86 & 40,32 & 16837000 & 41,19 & 41,30 & Venda & $-5,24 \%$ \\
\hline $16 / 4 / 2012$ & 42,14 & 42,28 & 41,02 & 41,24 & 20908500 & 41,42 & 41,32 & Compra & $0 \%$ \\
\hline $4 / 5 / 2012$ & 41,08 & 41,08 & 39,98 & 40,44 & 23400100 & 41,55 & 41,59 & Venda & $-1,94 \%$ \\
\hline $8 / 6 / 2012$ & 36,93 & 37,47 & 36,9 & 37,33 & 16845500 & 36,42 & 36,41 & Compra & $0 \%$ \\
\hline $16 / 7 / 2012$ & 39,32 & 39,32 & 39,32 & 39,32 & 0 & 39,11 & 39,20 & Venda & $5,30 \%$ \\
\hline $13 / 8 / 2012$ & 37,71 & 38,05 & 37,48 & 37,66 & 10031000 & 37,26 & 37,05 & Compra & $0 \%$ \\
\hline $20 / 8 / 2012$ & 34,91 & 34,91 & 34,91 & 34,91 & 0 & 36,05 & 36,41 & Venda & $-7,30 \%$ \\
\hline $13 / 9 / 2012$ & 36 & 37,64 & 35,7 & 37,29 & 34913200 & 35,12 & 34,13 & Compra & $0 \%$ \\
\hline $2 / 10 / 2012$ & 35,55 & 35,89 & 34,86 & 35,15 & 12733100 & 35,63 & 35,94 & Venda & $-5,74 \%$ \\
\hline $16 / 10 / 2012$ & 36,43 & 37,46 & 36,35 & 36,95 & 26721400 & 36,15 & 36,10 & Compra & $0 \%$ \\
\hline $24 / 10 / 2012$ & 34,62 & 34,79 & 34,07 & 34,29 & 13386000 & 35,59 & 35,69 & Venda & $-7,20 \%$ \\
\hline $31 / 10 / 2012$ & 36,5 & 36,55 & 35,88 & 36,35 & 14306000 & 35,78 & 35,76 & Compra & $0 \%$ \\
\hline $15 / 11 / 2012$ & 35,63 & 35,63 & 35,63 & 35,63 & 0 & 36,07 & 36,13 & Venda & $-1,98 \%$ \\
\hline $3 / 12 / 2012$ & 36,92 & 36,92 & 36,1 & 36,68 & 21735900 & 36,00 & 35,92 & Compra & $0 \%$ \\
\hline \multicolumn{9}{|c|}{ Total } & $-21 \%$ \\
\hline
\end{tabular}

Fonte: Economática, elaborado pelo autor, 2014.

As indicações de compra e venda, para as ações da Vale PN, foram apresentadas anteriormente no Quadro 10. Vale apregoar que o mês de Outubro foi aquele com maior número de sinalizações (4 no total), sendo duas de compra e duas de venda. As sinalizações acima dispostas demonstram que o investidor deveria comprar no dia 04/01/2012 e fazer várias transações ao longo do ano, objetivando maior retorno em conformidade com o mecanismo das Médias Móveis, sendo a primeira venda dia 20/02/2012. 
Os Quadros 11 e 12 apresentados a seguir, representam as sinalizações de média móvel para as ações ordinárias das empresas Vale e Petrobrás, havendo maior número de sinais para operações, na Vale ON, no mês de Outubro, e na Petrobrás em Junho, ambos os meses com 4 sinalizações:

Quadro 11 - Médias Móveis da Vale ON

\begin{tabular}{|c|c|c|c|c|c|c|c|c|c|}
\hline \multicolumn{10}{|c|}{ Vale ON } \\
\hline Data & Abertura & Máx & Mín & Fechamento & Volume & MM5 & MM20 & Sinal & Resultado \\
\hline $5 / 1 / 2012$ & 42,51 & 42,76 & 41,63 & 41,86 & 2954200,00 & 41,11 & 40,44 & Compra & $0 \%$ \\
\hline $17 / 2 / 2012$ & 43,8 & 43,95 & 42,51 & 42,93 & 5705400,00 & 44,23 & 44,30 & Venda & $2,56 \%$ \\
\hline $22 / 3 / 2012$ & 41,95 & 42,06 & 41,24 & 41,57 & 4018600,00 & 42,74 & 42,72 & Compra & $0 \%$ \\
\hline $23 / 3 / 2012$ & 41,53 & 41,88 & 41,38 & 41,55 & 2429700,00 & 42,51 & 42,61 & Venda & $-0,48 \%$ \\
\hline 2/4/2012 & 42,99 & 44,43 & 42,84 & 44,01 & 5340200,00 & 42,24 & 42,05 & Compra & $0 \%$ \\
\hline $10 / 4 / 2012$ & 41,41 & 41,54 & 40,63 & 41,24 & 3599400,00 & 42,19 & 42,40 & Venda & $-6,29 \%$ \\
\hline $17 / 4 / 2012$ & 42,45 & 43,33 & 42,17 & 43,06 & 5456000,00 & 42,46 & 42,33 & Compra & $0 \%$ \\
\hline $7 / 5 / 2012$ & 41,02 & 41,63 & 41,00 & 41,50 & 2809000,00 & 42,54 & 42,65 & Venda & $-3,62 \%$ \\
\hline $11 / 6 / 2012$ & 38,61 & 38,97 & 37,75 & 37,86 & 3991800,00 & 37,61 & 37,36 & Compra & $0 \%$ \\
\hline $13 / 7 / 2012$ & 39,72 & 40,42 & 39,61 & 40,23 & 3391600,00 & 40,03 & 40,13 & Venda & $6,26 \%$ \\
\hline $13 / 8 / 2012$ & 38,65 & 38,96 & 38,31 & 38,61 & 2988300,00 & 38,03 & 37,79 & Compra & $0 \%$ \\
\hline 20/8/2012 & 35,65 & 35,65 & 35,65 & 35,65 & 0,00 & 36,88 & 37,17 & Venda & $7,67 \%$ \\
\hline $12 / 9 / 2012$ & 36,99 & 37,55 & 36,33 & 37,28 & 7138400,00 & 34,93 & 34,69 & Compra & $0 \%$ \\
\hline $2 / 10 / 2012$ & 36,7 & 37,02 & 35,94 & 36,19 & 3520500,00 & 36,69 & 36,85 & Venda & $-2,92 \%$ \\
\hline $16 / 10 / 2012$ & 37,6 & 39,08 & 37,60 & 38,11 & 12119400,00 & 37,28 & 37,20 & Compra & $0 \%$ \\
\hline $24 / 10 / 2012$ & 35,75 & 35,95 & 35,01 & 35,32 & 3446400,00 & 36,75 & 36,80 & Venda & $-7,32 \%$ \\
\hline $31 / 10 / 2012$ & 37,4 & 37,73 & 37,00 & 37,45 & 6709800,00 & 36,88 & 36,87 & Compra & $0 \%$ \\
\hline $15 / 11 / 2012$ & 36,59 & 36,59 & 36,59 & 36,59 & 0,00 & 37,03 & 37,20 & Venda & $-2,30 \%$ \\
\hline 4/12/2012 & 37,65 & 37,65 & 36,48 & 36,70 & 5039500,00 & 36,96 & 36,81 & Compra & $0 \%$ \\
\hline \multicolumn{9}{|c|}{ Total } & $-6 \%$ \\
\hline
\end{tabular}

Fonte: Economática, elaborado pelo autor, 2014.

Quadro 12 - Médias Móveis da Petrobras ON

\begin{tabular}{|c|c|c|c|c|c|c|c|c|c|}
\hline \multicolumn{10}{|c|}{ Petrobras ON } \\
\hline Data & Abertura & Máx & Mín & Fechamento & Volume & MM5 & MM20 & Sinal & Resultado \\
\hline $6 / 1 / 2012$ & 24,10 & 24,35 & 23,91 & 24,00 & 3454500,00 & 23,68 & 23,58 & Compra & $0 \%$ \\
\hline $14 / 2 / 2012$ & 26,10 & 26,10 & 24,70 & 24,89 & 8522000,00 & 26,67 & 26,85 & Venda & $3,70 \%$ \\
\hline $5 / 3 / 2012$ & 26,36 & 26,50 & 25,64 & 25,82 & 6098200,00 & 25,94 & 25,90 & Compra & $0 \%$ \\
\hline $12 / 3 / 2012$ & 24,64 & 25,01 & 24,63 & 24,68 & 7193400,00 & 25,13 & 25,42 & Venda & $-4,42 \%$ \\
\hline $4 / 5 / 2012$ & 22,26 & 22,36 & 21,06 & 21,40 & 9448500,00 & 22,46 & 22,44 & Compra & $0 \%$ \\
\hline $7 / 5 / 2012$ & 21,45 & 21,65 & 20,90 & 21,50 & 7382700,00 & 22,32 & 22,35 & Venda & $0,47 \%$ \\
\hline $7 / 6 / 2012$ & 20,00 & 20,00 & 20,00 & 20,00 & 0,00 & 19,81 & 19,79 & Compra & $0 \%$ \\
\hline $13 / 6 / 2012$ & 19,34 & 19,67 & 19,12 & 19,63 & 9026800,00 & 19,63 & 19,68 & Venda & $-1,85 \%$ \\
\hline $21 / 6 / 2012$ & 20,85 & 20,90 & 19,97 & 19,97 & 5676600,00 & 19,66 & 19,62 & Compra & $0 \%$ \\
\hline $27 / 6 / 2012$ & 18,60 & 18,78 & 18,23 & 18,24 & 5556800,00 & 19,57 & 19,58 & Venda & $-8,66 \%$ \\
\hline $6 / 7 / 2012$ & 20,00 & 20,14 & 19,72 & 19,88 & 4260100,00 & 19,50 & 19,36 & Compra & $0 \%$ \\
\hline $27 / 7 / 2012$ & 20,01 & 20,80 & 19,87 & 20,80 & 5393000,00 & 19,56 & 19,63 & Venda & $4,63 \%$ \\
\hline $30 / 7 / 2012$ & 20,67 & 21,00 & 20,34 & 21,00 & 4635200,00 & 19,77 & 19,72 & Compra & $0 \%$ \\
\hline $3 / 9 / 2012$ & 21,42 & 21,62 & 21,10 & 21,40 & 2860800,00 & 21,84 & 21,95 & Venda & $1,90 \%$ \\
\hline $13 / 9 / 2012$ & 22,73 & 23,93 & 22,67 & 23,90 & 11702100,00 & 22,21 & 22,01 & Compra & $0 \%$ \\
\hline $5 / 10 / 2012$ & 23,45 & 23,50 & 23,00 & 23,10 & 3997500,00 & 23,32 & 23,36 & Venda & $-3,35 \%$ \\
\hline $18 / 10 / 2012$ & 23,44 & 23,53 & 23,13 & 23,50 & 7146100,00 & 23,50 & 23,40 & Compra & $0 \%$ \\
\hline $23 / 10 / 2012$ & 22,80 & 22,83 & 22,21 & 22,50 & 5528200,00 & 23,32 & 23,34 & Venda & $-4,25 \%$ \\
\hline $12 / 12 / 2012$ & 20,16 & 20,28 & 19,88 & 20,06 & 9425200,00 & 19,59 & 19,55 & Compra & $0 \%$ \\
\hline \multicolumn{9}{|c|}{ Total } & $-12 \%$ \\
\hline
\end{tabular}

Fonte: Economática, elaborado pelo autor, 2014.

O Quadro 13 delineado adiante, é uma representação das médias móveis obtidas para as ações ordinárias da empresa BM\&FBovespa. As operações de compra e venda seriam realizadas ao longo do ano, baseadas nas médias móveis para 5 e 20 dias, iniciando no dia 
09/01/2012 com compra e já em 27/02/2012 se realizaria uma ordem de venda, maximizando assim a rentabilidade obtida.

Quadro 13 - Médias Móveis da BMF Bovespa ON

\begin{tabular}{|c|c|c|c|c|c|c|c|c|c|}
\hline \multicolumn{10}{|c|}{ BMF Bovespa ON } \\
\hline Data & Abertura & Máx & Mín & Fechamento & Volume & MM5 & MM20 & Sinal & Resultado \\
\hline $9 / 1 / 2012$ & 10,15 & 10,31 & 10,1 & 10,3 & 9344700 & 9,98 & 9,97 & Compra & $0 \%$ \\
\hline $27 / 2 / 2012$ & 11,64 & 11,73 & 11,5 & 11,65 & 14608300 & 11,74 & 11,75 & Venda & $13,11 \%$ \\
\hline $8 / 3 / 2012$ & 12,22 & 12,39 & 12,21 & 12,29 & 14700900 & 11,90 & 11,84 & Compra & $0 \%$ \\
\hline 23/3/2012 & 11,87 & 12,02 & 11,76 & 11,84 & 10924000 & 12,02 & 12,05 & Venda & $-3,66 \%$ \\
\hline $7 / 6 / 2012$ & 10 & 10 & 10 & 10 & 0 & 9,61 & 9,59 & Compra & $0 \%$ \\
\hline $26 / 6 / 2012$ & 9,85 & 10,03 & 9,63 & 9,95 & 11093600 & 9,96 & 10,03 & Venda & $-0,50 \%$ \\
\hline 4/7/2012 & 11 & 11,3 & 10,93 & 11,22 & 7235900 & 10,36 & 10,25 & Compra & $0 \%$ \\
\hline $26 / 7 / 2012$ & 10,93 & 11,33 & 10,9 & 11,3 & 12141800 & 10,87 & 10,94 & Venda & $0,71 \%$ \\
\hline $31 / 7 / 2012$ & 11,75 & 11,88 & 11,4 & 11,5 & 8815200 & 11,31 & 11,15 & Compra & $0 \%$ \\
\hline $29 / 8 / 2012$ & 11,56 & 11,61 & 11 & 11,13 & 20492600 & 11,72 & 11,78 & Venda & $-3,22 \%$ \\
\hline $12 / 9 / 2012$ & 11,69 & 11,7 & 11,55 & 11,6 & 9976700 & 11,59 & 11,57 & Compra & $0 \%$ \\
\hline $4 / 10 / 2012$ & 12,3 & 12,44 & 12,18 & 12,31 & 16516700 & 12,33 & 12,34 & Venda & $6,12 \%$ \\
\hline $15 / 10 / 2012$ & 12,9 & 13,05 & 12,75 & 12,92 & 9874800 & 12,67 & 12,60 & Compra & $0 \%$ \\
\hline $15 / 11 / 2012$ & 12,81 & 12,81 & 12,81 & 12,81 & 0 & 13,12 & 13,26 & Venda & $-0,85 \%$ \\
\hline $5 / 12 / 2012$ & 13,1 & 13,1 & 12,74 & 12,75 & 12635700 & 12,90 & 12,88 & Compra & $0 \%$ \\
\hline \multicolumn{9}{|c|}{ Total } & $12 \%$ \\
\hline
\end{tabular}

Fonte: Economática, elaborado pelo autor, 2014.

O Quadro 14 disposto abaixo amalgamou os resultados obtidos para o papel da PDG Realt ON, sendo os meses de julho e outubro aqueles com maior número de sinalizações. Em julho há sinais de 2 compras e uma venda, enquanto em outubro o movimento foi inverso (2 vendas e uma compra).

Quadro 14 - Médias Móveis da PDG Realt ON

\begin{tabular}{|c|c|c|c|c|c|c|c|c|c|}
\hline \multicolumn{10}{|c|}{ PDG Realt ON } \\
\hline Data & Abertura & Máx & Mín & Fechamento & Volume & MM5 & MM20 & Sinal & Resultado \\
\hline $5 / 1 / 2012$ & 6,3 & 6,41 & 6,15 & 6,29 & 17675700 & 6,16 & 6,10 & Compra & $0 \%$ \\
\hline $28 / 2 / 2012$ & 7,25 & 7,53 & 7,22 & 7,49 & 15778900 & 7,66 & 7,69 & Venda & $19,08 \%$ \\
\hline 9/5/2012 & 4,93 & 5,17 & 4,88 & 5,02 & 31686900 & 5,00 & 4,88 & Compra & $0 \%$ \\
\hline $15 / 5 / 2012$ & 3,95 & 4,04 & 3,64 & 3,67 & 67981300 & 4,70 & 4,76 & Venda & $-26,89 \%$ \\
\hline $14 / 6 / 2012$ & 3,5 & 3,59 & 3,38 & 3,39 & 36464400 & 3,36 & 3,33 & Compra & $0 \%$ \\
\hline $29 / 6 / 2012$ & 3,52 & 3,58 & 3,48 & 3,51 & 17614800 & 3,39 & 3,43 & Venda & $3,54 \%$ \\
\hline $6 / 7 / 2012$ & 3,51 & 3,56 & 3,34 & 3,38 & 23555100 & 3,51 & 3,48 & Compra & $0 \%$ \\
\hline $10 / 7 / 2012$ & 3,4 & 3,41 & 3,04 & 3,04 & 56223200 & 3,46 & 3,49 & Venda & $-10,06 \%$ \\
\hline $31 / 7 / 2012$ & 3,67 & 3,71 & 3,41 & 3,41 & 21632200 & 3,42 & 3,35 & Compra & $0 \%$ \\
\hline $2 / 10 / 2012$ & 3,87 & 3,89 & 3,62 & 3,7 & 27830700 & 3,95 & 3,99 & Venda & $8,50 \%$ \\
\hline $24 / 10 / 2012$ & 3,62 & 3,64 & 3,49 & 3,53 & 24898800 & 3,65 & 3,64 & Compra & $0 \%$ \\
\hline $29 / 10 / 2012$ & 3,41 & 3,44 & 3,31 & 3,41 & 8590800 & 3,57 & 3,58 & Venda & $-3,40 \%$ \\
\hline $6 / 12 / 2012$ & 3,05 & 3,2 & 3,03 & 3,17 & 42974400 & 3,06 & 3,04 & Compra & $0 \%$ \\
\hline
\end{tabular}

Fonte: Economática, elaborado pelo autor, 2014.

Depois de calcular as médias móveis foram determinados os indicadores de estatística descritiva, conforme Quadro 15, destacando-se o retorno médio das cotações, sua variância e as cotações mínimas e máximas de cada empresa. 


\begin{tabular}{|c|c|c|c|c|c|c|c|}
\hline & Quadro 15 - Retornos das ações \\
\hline & OGXP3 & PETR4 & VALE5 & VALE3 & PETR3 & BVMF3 & PDGR3 \\
\hline Retorno Médio & $-0,44 \%$ & $-0,05 \%$ & $0,02 \%$ & $0,01 \%$ & $-0,07 \%$ & $0,14 \%$ & $-0,24 \%$ \\
\hline Variância & $0,16 \%$ & $0,04 \%$ & $0,03 \%$ & $0,03 \%$ & $0,04 \%$ & $0,04 \%$ & $0,12 \%$ \\
\hline Mínimo & 4,25 & 17,64 & 32,12 & 32,45 & 18,24 & 9,1 & 2,81 \\
\hline Máximo & 18,21 & 25,6 & 43,97 & 45,87 & 27,75 & 14,3 & 8,09 \\
\hline
\end{tabular}

Fonte: Economática, elaborado pelo autor, 2014.

Feita a análise dos dados das ferramentas Fundamentalista e Técnica, foi possível asseverar que cada método apresenta sua importância e o período no qual cada técnica atua é bem delimitado, embora cada ferramenta, em alguns momentos, tenha apresentado resultados distintos. Desse modo a Análise Fundamentalista avalia as empresas em função do longo prazo, devido ao Demonstrativo Financeiro da firma ser apresentado em poucos períodos no ano, diante dos gastos operacionais para sua execução e do tempo para reunir os dados. Já a ferramentas Técnica contribui para as análises de curto prazo, uma vez que estas buscam antecipar os movimentos do mercado e auxiliam na identificação de tendências referentes aos ativos estudados.

Ressalte-se que os índices Fundamentalistas obtiveram resultados expressivos, os quais são interpretados abaixo, com intuito de obter um divisor comum a esta análise, respondendo, dentre as empresas estudadas, quais as que alcançaram os melhores/piores valores e destas, qual será a melhor escolha mediante a ferramenta Fundamentalista:

- BM\&FBovespa: Esta companhia apresenta melhor índice de participação de capital de terceiros, ou seja, tem menor dependência de recursos obtidos através de dívidas de curto ou longo prazo. Isso demonstra que a empresa detém quase $80 \%$ do capital utilizado para os seus investimentos e continuidade das atividades de origem própria, por meio de capital dos sócios (Patrimônio Liquido). Também possui um alto índice de liquidez geral, tendo em conta a expressiva quantidade de ativos de curto e longo prazo para fazer face as suas obrigações, sejam elas de curto ou longo prazo (o valor dos ativos totais supera mais de cinco vezes o valor dos passivos circulante e não circulante - -5,33). É possível ainda inferir que a empresa mantém os melhores índices de rentabilidade. Sua Margem Liquida traduz quanto a empresa consegue gerar de lucro a cada $\$ 1$ de vendas realizadas ou serviços prestados, valor que é superior ao das demais empresas da amostra, demonstrando eficiência operacional e capacidade em gerar lucros. A BM\&FBovespa também apresenta um índice de retorno do investimento superior às demais, o que evidencia maior capacidade de gerar lucro líquido tendo em conta os investimentos realizados pela empresa no período (Ativo Médio). 
- PDG Realt: Apresenta melhores resultados no que diz respeito aos indicadores ligados à imobilização, seja de capital próprio, seja quando observada a soma dos recursos não correntes. A empresa aplica uma parcela pequena de seu capital e também do capital de terceiros de longo prazo em ativos permanentes (investimentos, imobilizado e intangíveis). Esses índices não são relevantes se analisados isoladamente, pois o índice de imobilização de uma firma para outra varia de acordo com o ramo de atividade a que cada uma pertence. Nesse caso, a PDG Realt, por ser do segmento de construção civil, não tem necessidade de imobilizar um grande percentual de seu capital, diferentemente das empresas Vale e Petrobrás.

- Petrobrás: Apresentou indicadores médios, não obtendo destaque em qualquer índice. Alguns dos quocientes calculados com resultados menos expressivos referem-se àqueles do âmbito da rentabilidade, pois esta sociedade anônima foi capaz de gerar valores de margem líquida e retorno sobre os investimentos ínfimos. No entanto, gerou Lucro por Ação e Rendimento de Dividendos consideráveis, diferentemente das firmas PDG Realt e OGX Petróleo. A Petrobrás tem uma boa composição do endividamento, ou seja, apenas $21 \%$ da dívida total contraída é de curto prazo (vencimento em até um ano).

- Vale: Apresenta os melhores indicadores de mercado, isto é, o maior lucro por ação $(\$ 1,72)$ e $6,27 \%$ de rendimento de dividendos, o que demonstra imensa capacidade da empresa em gerar lucros e rendimentos aos acionistas. Além disso, a Vale tem um baixo endividamento de curto prazo ( $23 \%$ da dívida total) e baixa dependência de capital de terceiros (para cada $\$ 1$ de capital próprio, tem $\$ 0,71$ de dívidas totais), ou seja, utiliza para investimentos grande parcela do capital próprio (dos acionistas) e os remunera muito bem, seja via dividendos ou lucro por ação.

- OGX Petróleo: Apesar de ter forte dependência de capital de terceiros (para cada $\$ 1$ de capital próprio apresenta $\$ 1,21$ de dívidas), tem o melhor índice de composição de endividamento, pois apenas $13 \%$ dessa dívida total é de curto prazo. É esse uso de recursos de longo prazo que lhe proporciona bons indicadores de liquidez, relativamente a questões de capacidade de pagamento de longo prazo (liquidez corrente, seca e imediata). Todavia a liquidez geral da firma, determinada pela razão de ativos totais e passivos totais, demonstra que no curto prazo a empresa pode até apresentar bons indicadores de liquidez, mas em uma perspectiva de longo prazo essa sua capacidade fica reduzida, devido aos indicadores de margem líquida, retorno sobre o investimento e lucro por ação estarem negativados, além de não proporcionar rendimento de dividendos.

Foram calculadas também as médias móveis, retratadas nas tabelas anteriores, o que possibilitou demonstrar o tempo de compra/venda dos ativos analisados, visualizando, mediante as suas sinalizações, o momento ideal para efetuar as operações de cada ação 
observada. Portanto, as médias móveis auxiliam o investidor na tomada de decisão no mercado de capitais referente ao curto prazo.

As ferramentas utilizadas pela Análise Técnica ajudaram na análise de curto prazo das tendências que irão prevalecer no mercado, como, por exemplo, o método de suporte e resistência, que mede a força da tendência em romper com resistências impostas pelo mercado mantendo a sua trajetória.

As outras ferramentas, como Bandas de Bollinger e Índice de Força Relativa, possibilitaram analisar as oscilações do mercado mediante as escolhas dos agentes e rastrear o quanto o ativo estava sobre-comprado ou não para efetuar a tomada de decisão. Esses instrumentos, juntamente com todo o arcabouço técnico utilizado neste trabalho, ajudam os acionistas ao tomar suas decisões de curto prazo com maior assertividade e menores riscos.

Foi utilizada ainda estatística descritiva para analisar os retornos médios e a variância (volatilidade) que as ações analisadas apresentaram no ano analisado. A BM\&FBovespa exibiu um valor de $0,14 \%$ de retorno médio aos acionistas e obteve uma variância considerada baixa em relação às demais empresas, com uma porcentagem de $0,04 \%$, compreendendo que esta firma oscilou pouco, sendo segura para investir capital, destacando-se mediante aos indicadores estatísticos e outros indicadores fundamentalistas, o que a torna a melhor empresa para investimento (na série temporal analisada), assegurando maior rentabilidade em comparação às demais firmas da amostra.

Observa-se que as duas ferramentas utilizadas para a análise de ativos na tomada de decisão no mercado de capitais podem ser complementares, pois cada uma tem sua especificidade temporal, mas ambas atuam com intuito de diminuir os riscos e maximizar os acertos nas operações realizadas pelos acionistas. Desse modo a análise Fundamentalista é empregada no longo prazo, em que os dados são colhidos e os indicadores são gerados, por isso sua função é a de avaliar qual a melhor empresa para se investir e qual o grau de consolidação de suas atividades, tendo em vista seus fundamentos.

$\mathrm{Na}$ análise Técnica, avaliam-se as tendências das cotações dos ativos no curto prazo, pois suas ferramentas preveem as oscilações e tendências do mercado em um curto espaço de tempo. Há grande importância em fundir os dois métodos para atingir maiores êxitos no mercado de capitais, pois estas ferramentas, sendo operadas em conjunto no âmbito da análise econômico-financeiro e contábil, são capazes de diminuir a probabilidade do investidor de correr riscos e, por conseguinte, prejuízos no mercado. 
Vale considerar também que os indicadores contábeis e financeiros procuram demonstrar a capacidade da empresa em honrar seus compromissos e pagar suas dívidas, além de expressar qual a participação de capital de terceiros empregados na firma e sua composição, a lucratividade sobre as atividades operacionais e o rendimento dos acionistas, entre tantas outras análises que podem ser obtidas através dos indicadores Fundamentalistas. Já os outros indicadores, frutos da análise Técnica, permitem visualizar os sinais de confirmação das operações de compra/venda observadas no mercado e a tendência das cotações de tal ativo. Salienta-se que estas ferramentas podem influenciar uma a outra, por exemplo, caso ocorra algo de negativo no Demonstrativo Financeiro das empresas, isso pode ser refletido no mercado e, consequentemente, na cotação dos ativos, conforme a hipótese de mercados eficientes, que se constitui no espaço imaginário onde os preços acompanham as informações disponíveis e nenhum agente consegue auferir lucros superiores ao do preço de mercado, pois o valor das cotações reflete a estimação dos títulos no presente.

Verifica-se que a BM\&FBovespa obteve o resultado mais satisfatório, tanto nos indicadores Fundamentalistas e quanto nas análises Técnicas, pois utiliza capital próprio para investir em suas atividades, possuindo um alto índice de liquidez geral e entre as demais firmas possui o melhor índice de rentabilidade e retorno do investimento. Na análise Técnica, a BM\&FBovespa não obteve períodos longos de tendências de baixa e auferiu o maior retorno médio entre os ativos estudados. Por outro lado, a OGX Petróleo teve a menor consolidação nas suas atividades operacionais e apresentou uma forte linha de tendência de baixa por um período considerável no exercício, além de resultados não satisfatórios no que se refere à rentabilidade proporcionada aos acionistas, o lucro gerado no exercício e as variações nas cotações das ações no período analisado.

\section{CONSIDERAÇÕES FINAIS}

O mercado de capitais tem grande importância no cenário econômico mundial, pois permite um fluxo de capitais dos poupadores aos agentes deficitários, buscando auxiliar no desenvolvimento econômico de uma nação e estimulando o investimento e a formação de poupança. Com a ampliação desse mercado, por meio de expansão econômica, proliferação de sociedades anônimas, inserção de inovações financeiras e aumento expressivo no volume de capitais das sociedades existentes, faz-se de grande valia que os agentes se especializem cada vez mais para diminuírem os riscos e aumentarem os acertos em suas operações financeiras. Desse modo, os estudos das ferramentas Fundamentalista e Técnica auxiliam na tomada de 
decisão dos acionistas referente à avaliação da solidez econômico-financeira das firmas e o momento ideal para comprar ou vender os ativos que detêm.

Analisados à luz das análises Fundamentalista e Técnica, a empresa BM\&FBovespa apresentou os melhores índices, tornando-se a melhor escolha entre as organizações estudadas, enquanto que a OGX Petróleo foi a firma com os piores indicadores, pois não demonstrou consistência nos índices de estrutura de capital, liquidez geral e rentabilidade e encontrou-se em seu histórico de cotações uma grande tendência de baixa referente à análise Técnica. Diante da probabilidade elevada de recorrer em prejuízo por ser a pior empresa, não é indicada para o acionista investir os seus recursos financeiros.

Vale destacar que esta pesquisa compreendeu a análise dos ativos financeiros transacionados na BM\&FBovespa, através das Ferramentas Fundamentalista e Técnica, mostrando-se capaz de apresentar a complementaridade e discrepância destes dois modelos, ao auxiliar na tomada de decisão dos acionistas minimizando os riscos e aumentando a rentabilidade. Dessa feita, a análise Fundamentalista demonstrou ser uma ferramenta eficaz na tomada de decisões no longo prazo, pois para ser realizada depende dos demonstrativos financeiros das empresas e demanda tempo para recolher os dados, tabulá-los e realizar análises. Já a análise Técnica contribui no curto prazo, porque é capaz de evidenciar, por meio de gráficos, figuras, tendências, osciladores e rastreados, a importância da análise como método de previsão do mercado e de suas tendências.

Por fim, propõe-se, como sugestões de trabalhos futuros, a realização de um portfólio de ações, pois através do uso da teoria de Markowitz (1952) é possível compreender a covariância existente entre vários ativos que compõe uma carteira, otimizando-a com o intuito de formar um portfólio de variância mínima. Assim, tendo em conta a fronteira de eficiência, é possível combinar as ações distintas para cumprir com o propósito fundamental da análise econômica e financeira: proporcionar maior retorno e menor risco.

\section{REFERÊNCIAS}

ASSAF NETO, A. Mercado financeiro. 10. Ed. - São Paulo: Atlas, 2011.

ARAÚJO. R.L., MAIA. S.F. O papel da Análise Fundamentalista na formação de uma carteira de ações para investimentos: um estudo empírico nas empresas que compõem o índice imobiliário da BM\&F Bovespa. PROBEX, 2011.

BEIRUTH, A.X. et al. Análise fundamentalista e avaliação de empresas: uma investigação teórica e um estudo de caso na Aracruz Celulose. Artigo apresentado no X Fórum de Ciências Contábeis do Espírito Santo. Aracruz, 01 a 03 de junho, 2007. 
BODIE, Z.; KANE, A; MARCUS, A. Investments. 5.ed. Boston: McGraw-Hill, 2001.

CHAVES. D.A. T. e ROCHA. K. C. Análise Técnica e Fundamentalista: divergências, similaridades e complementariedades. Universidade de São Paulo, 2004. Artigo elaborado com base no trabalho de conclusão de curso entregue ao Departamento de Administração da Faculdade de Economia, Administração e Contabilidade, USP. Disponível em: http://www.ead.fea.usp.br/tcc/trabalhos/Artigo-DanielChaves-2004.pdf Acesso em 22 de julho de 2008.

COPELAND, T. et al. Avaliação de empresas - valuation: calculando e gerenciando o valor das empresas. 3.ed. São Paulo: Makron Books Ltda, 2002.

DAMODARAN, A. Investiment Valuation: Tools and Techniques for Determining the Value of Any Asset. 2 ed. New York: John Wiley \& Sons, 2002.

FACHIN, O. Fundamentos de metodologia. 4. ed. São Paulo: Saraiva, 2003.

FORTUNA, E. Mercado Financeiro: produtos e serviços /Eduardo Fortuna. - 19a ed. rev. e atual. - Rio de Janeiro: Qualitymark, 2013.

GALDI, F.C. Estratégias de Investimento em Ações Baseadas na Análise de Demonstrações Contábeis: É Possível Prever o Sucesso? Tese de Doutorado apresentada ao curso de Ciências Contábeis da FEA/USP, São Paulo: 2008.

GIL, A. C. Como elaborar projetos de pesquisa. São Paulo: Atlas, 1991.

LAGIOIA, U.C. Fundamentos do Mercado de Capitais. São Paulo: Atlas, 2007.

MARKOWITZ, H. Portfolio selection. Journal of Finance, v. 7, n. 1, p. 77-91, 1952

NORONHA, M. Análise Técnica: Teorias, Ferramentas, Estratégias. Rio de Janeiro: Editec, 1995.

PENMAN, S. H. Financial statement analysis and security valuation. 2. ed. Boston: Irwin Mc Graw Hill, 2004.

PINHEIRO, J.L. Mercado de capitais: fundamentos e técnicas. - 3. Ed. - São Paulo: Atlas, 2005 .

ROTELLA, R. P., The Elements of Successful Trading, New York: Institute of Finance Simon\&Schuster, 1992.

SCHROEDER, R.G.; CLARK, M.W.; e CATHEY, J.M. Financial accounting Theory and Analysis: text reading and cases. USA: Willey, 2005.

VIDOTTO. R. S., MIGLIATO, A.L.T, ZAMBON, A.C. O moving average convergencedivergence como ferramenta para a decisão de investimentos no mercado de ações. ANPAD. RAC, Curitiba, v. 13, n. 2, art. 7, p. 291-309, Abr./Jun. 2009. 
VILLASCHI. A. W., GALDI, F. C., NOSSA, S. N. Análise Fundamentalista para seleção de uma carteira de investimento em ações com baixa razão Book-To-Market. Revista de Administração e Contabilidade da Unisinos. Out/Dez 2011.

YANG, S; e SATCHELL, S. The impact of technical analysis on asset price dynamics. Reino Unido: University of Cambridge. working paper, august, 2003.

WINGER, B. ; FRASCA, R. Investments: Introduction to analysis and Planning, 3. ed. Englewood Cliffs: Prentice Hall,1995. 